\title{
La identidad como proceso de construcción. Reapropiaciones de textualidades isabelinas a la luz de la farsa porteña
}

Resumen / La identidad como proceso de construcción. Reapropiaciones de textualidades isabelinas a la luz de la farsa porteña.

La identidad como un proceso de construcción, tal como se titula este ensayo es su tema central. Pero desde su inicio la autora señala que esa construcción es sumamente compleja pues en ella pugnan dos aspectos diferentes que se integran, el de la identidad propia y al mismo tiempo en relación al campo cultural de los países centrales. Hace su análisis desde las textualidades las isabelinas que si bien no tuvieron origen en América han resultado muy productivas en estas culturas, generando múltiples relecturas que ponen en crisis modelos hegemónicos de cómo se conciben el poder, los lazos sociales y familiares. La intención del artículo es re-elaborar algunas apropiaciones de las textualidades shakesperianas y su re-elaboración para metaforizar momentos coyunturales y traumáticos de la historia latinoamericana.

\section{Palabras clave}

Historia - identidad - Latinoamérica - textualidad.

Summary / Identity as a construction process. Re-creating elizabethan drama through Buenos Aires farce.

The identity consider like a construction process, is the central subject of this essay. But from its beginning the author indicates that this construction is extremely complex and at the same time struggle two different aspects that integrate themselves, the one of the own identity and the other in relation to the cultural field of the central countries. She makes this analysis from the elizabethan drama that even have not been origined in America they have been very productive in these cultures, generating multiple readings that put in crisis hegemonic models of how they conceive the power, the social and familiar bows. The intention of the article is re- elaborate some appropriations of shakesperian texts to recreate metaphoric and traumatic moments of Latin American history.

\section{Key words}

History - identity - Latin America - textualidad.

Resumo / A identidade como processo de construção. Reapropiaciones de textualidades isabelinas à luz da farsa porteña.

A identidade como um processo de construção, tal qual o título deste ensáio, é seu tema central.

Mas desde seu início a autora assinala que essa construção é sumamente complexa pois nela batalham dois aspectos diferentes que se integram, o da identidade própia e ao mesmo tempo em relação ao campo cultural dos paísses centráis. Faz seu analisse desde as textualidades das isabelinas que se bem não tiveram origem em América resultaram muito produtivas nestas culturas, gerando múltiples releituras que põem em crise modelos hegemônicos de como se concebem o poder, laços sociais e familiares.

A intenção do artigo é re elaborar algumas apropriações das textualidades shakesperianas e seu re elaboração para metaforizar momentos cojunturais e traumáticos da história latinoamericana.

\section{Palavras clave}

História - identidade - Latinoamérica - textualidade.

\footnotetext{
* Licenciada en Artes (UBA). Profesora de Enseñanza Media y Superior en Artes (UBA). Profesora regular de la Facultad de Diseño
} y Comunicación de la Universidad de Palermo. Es docente en otras Universidades e Instituciones. Es actriz y directora teatral. 


\section{Introducción}

Al plantearnos el problema de la búsqueda de una identidad latinoamericana nos sumergimos necesariamente en la lógica de un proceso dinámico en permanente construcción: somos todos esos rostros que se entrecruzan y buscan sintetizarse, pero como todo proceso dialéctico esa síntesis nunca permanecerá estanca y continuará así redefiniéndose hasta el fin de los tiempos, si es que alguna vez hay un fin.

¿Pero en esa mezcla de valores, de imágenes, de culturas que nos hacen ser lo que somos hay algo que nos hace específicos, que marque una diferencia respecto de los Otros?

A lo largo de nuestra historia hemos ido construyendo imágenes de nosotros mismos, buscando rostros que nos definan como país, como continente y estas imágenes se han formado con tradiciones, valores que lograron constituir un nomos, un orden significativo común (Berger:33) que nos define como grupo, que nos hace sentirnos parte de nuestra cultura, de nuestro grupo social. Si circunscribimos el problema al campo del arte y del diseño, los artistas y diseñadores latinoamericanos, sean argentinos o de otro país latinoamericano, siempre han estado pugnando por buscar una identidad propia pero al mismo tiempo, intentando lograr un reconocimiento desde el campo intelectual que como países periféricos, siempre se estructuró en relación al campos culturales centrales. Nuestro sistema teatral ha trabajado en muchas ocasiones en relación a las intertextualidades europeas. Creemos que si hay algo que nos define es el cruce, la mezcla, somos fruto del cruce de culturas, de apropiaciones de textos ajenos. Ahora bien, desde los comienzos de la historia, ha existido un interés, incluso una fascinación por la cultura del otro: ya en la antigüedad los mismos romanos tomaron la cultura griega, incluso su cosmogonía y la latinizaron. Esta forma de contacto, de encuentro entre "nomos" diferentes enriquece a ambas culturas, es más creemos que todo lo que tiende a lo puro y a anquilosarse sobre sí mismo ha llevado a las peores experiencias sociales en la historia humana. El tema sería analizar las instancias de poder en las que estas apropiaciones se llevan a cabo y los juegos hegemónicos que se plantean en dichos intercambios, porque no siempre el encuentro de culturas es simétrico.

En América Latina, por ejemplo, la llamada conquista se caracterizó por arrasar con las culturas existentes y en algunos casos estas últimas se extinguieron completamente. En nuestro origen, nuestro propio nombre se erige como el nombre que silencia los miles de otros nombres con que era llamado este territorio antes de la llegada europea. El idioma que adoptamos como propio y que nos define como latinoamericanos también lo adoptamos, lo transformamos, lo americanizamos pero provino de otro espacio. En algún lugar, nosotros como Calibán, para comunicarnos utilizamos un lenguaje que nos fue impuesto y que ahora reconocemos como nuestro. Desde los comienzos, entonces, al tratar de buscarnos nos vimos en la necesidad de ser nosotros en lo ajeno. Es por esto, que me interesa este concepto de apropiación de textos, de imágenes, de objetos, de representaciones que son oriundas de un espacio otro, pero que al tomarlas y resignificarlas nos devuelven la imagen, de lo que somos. Ahora bien, la representación y la construcción de imágenes no es inocente, no es pura, ni transparente, la transparencia es una ilusión como cualquier otra. Siempre hay un dispositivo de construcción que se instaura como hegemónico y que trata de borrar sus marcas de construcción, pero que sea considerado como válido en un momento dado, no quiere decir que no haya otras formas de concebir la cultura, ni la sociedad, ni lo que llamamos realidad Entonces, las representaciones son, en definitiva, un problema de "poder".

Es por esto que analizaremos en este trabajo un cierto tipo de textualidades, las isabelinas, que definitivamente no tuvieron origen en nuestro continente, pero que resultaron ser de las más productivas en nuestras culturas, generando múltiples relecturas que ponen en crisis modelos hegemónicos de cómo se conciben el poder, los lazos sociales y familiares. Es la intención de este trabajo re-elaborar algunas apropiaciones de las textualidades shakesperianas y su re-elaboración para metaforizar momentos coyunturales y traumáticos de nuestra historia.

\section{La farsa y la política}

Comenzaremos por analizar el rol de los locos y los bufones en las textualidades isabelinas, más concretamente en Rey Lear de Shakespeare para abordar la re-creación llevada a cabo en la actualidad con la puesta de Jorge Lavelli (2006)

Según el autor Trillo Figueroa, quien analiza la locura en los personajes shakespereanos, desde el punto de vista político, en el contexto histórico del teatro isabelino habría una correlación entre razón y poder, la razón tendría un estatuto de soberana y el poder de autoritario, por consiguiente la locura, en este esquema, sería equiparable a la idea de subversión constituyendo una metáfora de rebelión política. Los bufones están llamados a ridiculizar las certidumbres de una época, dándonos la posibilidad de apreciar el sinsentido del mundo.

La filosofía de los bufones es, precisamente, aquella que en cada época señala como dudoso lo que pasa por más inamovible, revela las contradicciones de lo que parece cierto e indiscutible, ridiculiza las certidumbres del sentido común y encuentra la razón en lo absurdo. (Kott:199)

Lear pierde la razón cuando ve la sinrazón de su orden, entonces habla como un bufón y el bufón lo abandona.

Según Trillo Figueroa podríamos hacer una interpretación de la locura de Lear en clave política:

En la obra se presenta la caída de una determinada noción de soberanía $[\ldots]$ a través de la representación de la desilusión del propio monarca. Lear muestra desde el principio su descontento por la organización política y está decidido a crear una nueva. Por lo que idea un experimento que pondrá a prueba las estructuras y lealtades de ese orden. (Trillo Figueroa: 327)

En este experimento, divide su reino, se despoja de su corona y pierde su lugar social. En el mundo de castas de la Edad Media, donde aún no se construye la noción de "individuo", uno se define en relación al lugar que ocupa en la sociedad, al perder ese lugar, uno pierde su esencia.

Bufón: [...] Tío, dame un huevo y te daré dos coronas. Lear: ¿Qué coronas serían?

Bufón: ¡Pardiez! Después de haber partido el huevo en dos mitades y comídome la sustancia, las dos coronas del cascarón. Cuando partiste en dos tu corona y diste una y otra parte, hiciese lo mismo que aquel que en un sendero lleno de fango se carga el burro a cuestas. Tenías poco seso debajo de tu corona calva, cuando abdicaste de la de oro [...] Ahora no eres más que un cero sin otra cifra. Yo estoy ahora mejor que tú, soy un loco, y tú no eres nada. (Shakespeare: 1640) 
Nos interesa Lear porque es un personaje que está en un mundo de transición, es un personaje que ha perdido su lugar en la sociedad, el lugar que le daba una identidad: la de rey y que se encuentra en el proceso de búsqueda de la suya propia y esto sólo es posible cuando se despoja de sus atributos. El trayecto de Lear será, como el trayecto del héroe, en búsqueda de su identidad, un trayecto de despojos, hasta llegar a la Naturaleza, a la animalización. Asistimos de esta forma a la desmitificación de la figura más sagrada de los tiempos isabelinos: el rey. Aquel que supo estar más alto, está ahora en lo más bajo. Esta es una temática reiterada en los textos isabelinos, no solamente en Shakespeare, pensemos en Eduardo // de Marlowe.

Pero, indaguemos los procedimientos a través de los cuales se trabaja esta desmitificación. Una de las formas que tienen las culturas subalternas de erosionar los valores hegemónicos es a través de lo que Bajtín llama la carnavalización, poner el mundo patas para arriba, desacralizando lo elevado, rebajándolo. La risa, cumple un rol vital en este proceso.

La verdadera risa, ambivalente y universal, no excluye lo serio, sino que lo purifica y lo completa. Lo purifica del dogmatismo, de la uniteralidad, de esclerosis, de fanatismo y de espíritu categórico [...] La risa impide a lo serio la fijación (Bajtín:112).

Esta era la función de los personajes de El loco y el Bufón cumplían este rol el las fiestas populares de la Edad Media.

De allí que todas las formas y símbolos de la lengua carnavalesca estén impregnadas del lirismo de la sucesión y de la renovación, de la gozosa comprensión de la relatividad de las verdades y las autoridades dominantes. Se caracteriza principalmente por la lógica original de las cosas "al revés" y "contradictorias", de las permutaciones constantes de lo alto y lo bajo (la "rueda") del frente y el revés, y por las diversas formas de parodias, inversiones, degradaciones, profanaciones, coronamientos y derrocamientos bufonescos (Bajtín: 16)

Nos parece en este punto relevante la re-lectura que planteó Jorge Lavelli en su puesta de Rey Lear en el Complejo Teatral de Buenos Aires, 2006, cuya adaptación textual estuvo a cargo de Patricia Zangaro. Lavelli tomó esta textualidad sobre la descomposición de una familia y la caída de una sociedad desde una mirada en donde lo farsesco acentúa la desmitificación del texto original.

Hay en la elección de Lavelli una propuesta estética que apuesta por el tono jocoso, distanciado, desmitificador. Me interesa recalcar la propuesta actoral. Los códigos de actuación elegidos le dan a esta versión una impronta que podríamos llamar porteña y que proviene de los sótanos de los 80. Alejandro Urdapilleta, quien encarna a Lear, en esta versión, es un reconocido actor undergroud, que tiene una larga trayectoria en el teatro off y ha logrado un reconocimiento en el teatro canonizado oficial, pero en este trayecto que ha incluido también apariciones televisivas, siempre ha mantenido su sello personal en la forma de encarar la actuación. Podríamos decir que el texto Urdapilleta se une al texto Leary ambos salen transformados.

El texto Urdapilleta tiene en sí la lógica de la desmitificación, sus producciones anteriores están teñidas con esta impronta, desde sus espectáculos con Tortonese y Batato Barea en el Parakultural, pasando por sus intervenciones en el programa de Gasalla y sus espectáculos con Tortonese:
Kara: Le voy a preparar un trono. ¿Con el tacho?

Karen: Mmmmm. Ahí, en el silloncito Chesterton. Para que pueda ver toda la mansión, con las alas de brillante, las pelota-paletas, las bow-windows... Esto tiene que ir más de contraste.

Kara: Karen, ¿sabés a quien invité? A Kafka y a Kuitca. Yo decía meterlos acá, abajo del sobretodo.

Karen: Y Rousseau y Rousselot por allá. Mirá que después va a venir toda esa caterva de franceses, que son raros, y además fuman cosas raras. Yo te advierto: son raros. Como por ejemplo Flaubert, Rimbaud, Mallarmé, Apollinaire, Jean Genet, Jean Cocteau, Cocó Chanel, Madame Bovary, Molière, Gigí Ruá...

Kara:...Jean Jaurés...

Karen:...Marguerite Duras, Marguerite Yourcenaire, Marguerite Tereré...

Kara: ... Cuchá-Cuchá...

Karen:... Malraux...

Kara:...Jean-Pierre Noere..., Gigigigig...

Karen:... Gigí Rua..

Kara: Y la infaltable, la principal de todas...

Juntas: Tini de Boucourt

Karen: O la lá, qu'est que c'est, andá a cagar...

Kara: Yo estoy re loca. A mí me pegó el querosén, Karen. (Tortonese, Urdapilleta: La moribunda)

En este texto vemos claramente el sentido profanatorio de la farsa, los autores canonizados, son re-bajados por relación de contigüidad con políticos corruptos, una actriz popular, nombres de calles. Esta profanación se da desde el uso del lenguaje pero también desde una lógica de la actuación, de un estilo que rescata lo carnavalesco, lo escatológico, lo corporal como una forma de provocar la risa, la carcajada de la que habla Bajtín.

El texto de Shakespeare, en Rey Lear, trabaja la lógica de la locura pero desde un lugar de un texto canonizado, la propuesta de actuación, los signos de caracterización, rescatan y resignifican esta lógica. Esos rostros blanqueados que remiten a una máscara nos marcan un extrañamiento, un personaje que se cita a sí mismo como personaje.

A la forma de actuación se le agregan ciertas imágenes de construcción en la puesta que trabajan el contexto.

Pensemos en la dimensión que adquiere la escena de la tempestad del Rey, junto con el bufón y Glocester. Los tres son unos despojados, unos marginales y Lavelli los coloca en un carro.

Lavelli: Se puede ver al mundo sin verso, como ese personaje ciego. La ciudad está invadida por mendigos. Anoche tarde iba caminando por Corrientes y la calle que nunca duerme era un gran dormitorio. Es doloroso. Lo mismo se ve en otras partes: el capitalismo devastador crea esa increíble riqueza para pocos y la ilusión de que todos pueden gozar de ella, y debajo de la pirámide quedan esas personas como gusanos en la calle (Inberg: 2).

En el hacer a Shakespeare nuestro contemporáneo, nuestra coyuntura social y política, actualiza loa textos resignificándolos. Me interesa recalcar otra apropiación de un texto de Shakespeare que utiliza el problema del poder político para hablar de la Argentina del 2001: en Volumnia, la versión de Pavlovsky sobre Coriolano de Shakespeare, vemos que hay un intento de transformar a Coriolano en un personaje positivo y al hacerlo cambiaría también el rol de la plebe. Al respecto dice Pavlovsky: 
En mi versión, Coriolano quiere expresar que la chusma triste y resignada puede devenir alegre y danzarina, puede reír a carcajadas, adquirir una nueva potencia que desconocía. Puede ser revolucionaria. En ese sentido el hombre debería luchar toda la vida para realizarse en hombre potente y creador. Cada hombre tiene la potencia de un superhombre. Un devenir superhombre. Las circunstancias históricas sociales han impedido que un gran sector de la humanidad llegara a este estado. Al de la potencia creadora. Luchar contra ese destino trágico es la idea de Coriolano. (Dubatti:9)

En este replanteo de las características del personaje de Coriolano, juega un rol primordial el punto de vista de Volumnia, su madre, quien lo insta a ser un hombre grande frente al mediocre, definido este último como alguien que posee un ritmo cardíaco regular alguien que ahorra para morir tranquilo, aquel que vive la vidita

Volumnia: La vidita es la vida chica - la de los romanos mediocres burocráticos - la que viven los hombres sin ambiciones - los que no saben soñar - los resignados, los que siempre se quejan y están tristes. Es un ejército muy grande.

Al frente de este ejército de mediocres y destacándose sobre el resto Volumnia ubica a su hijo

Volumnia: De qué te quejas Virgilia. Tienes al más grande y te quejas como si quisieras transformar su grandeza en la rutina de un hombre común isin extrasístoles y sin pedos! Y el ahorro Virgilia iel ahorro! ipara quién para qué!

Tan corta es la vida Virgilia que los hombres mediocres juntan con mezquindad su dinero toda la vida.

Los ahorristas que hacen de su vida la retención de su dinero - convierten el dinero en dioses a los que veneran como dioses del Olimpo.

Para asegurarse su vejez en una vida mediocre. Se pasan ahorrando para morir tranquilos. (Pavlovsky: 55)

La plebe maloliente de la versión de Shakespeare se transformó en pequeños burgueses ahorristas y en una visión crítica de la clase media argentina en pleno contexto de cacerolazos y corralito.

El texto plantea anacronismos, extrapola la historia de Coriolano que como sabemos se desarrolló en la transición de la monarquía a la república a la época del Imperio, Volumnia hace alusión a Julio César igualando a su hijo en cuando el primero fue bastante posterior a Coriolano y se habla de Volumnia como de la ideóloga más clara del imperio (Pavlovsky: 69) cuando Roma recién entraba a la República.

En la presentación de Coriolano como la figura del guerrero, hay una inversión de los valores romanos, Barrow plantea que lo que define al romano es la mentalidad del campesino-soldado

"Si asume una actitud política violenta será con el fin de conseguir, cuando las guerras terminen, tierra para labrar y una casa donde vivir." (Barrow:14)

La familia es el ámbito de desarrollo del romano, él es el paters familias y siempre hay una visión idealizada del retorno al hogar. En cambio, el general Coriolano de Pavlovsky sólo se siente a gusto entre la sangre de los enemigos, la guerra es su normalidad y la paz le provoca convulsiones
Coriolano: [...] sólo soy combate y los golpes y el ruido de la espada por los aires - allí me siento vivo - como si la vida donde existo sea el combate - todo lo demás me aterra - todo lo que me rodea madre mujer hijos amigos son como figuras planas de una escenografía que no logro encarnar [...] y cuando invento la próxima lucha vuelvo a ser yo aunque por instantes para seguir el juego - en medio de tanta mascarada vacía de agonía y de eso tan extraño que Ilaman patria y familia.

Esto que es impensable en boca de un romano, Pavlovsky lo utiliza para provocar un efecto de extrañamiento.

Coriolano es presentado como un mentiroso: miente cuando conquista Corioles proclamándose héroe cuando la ciudad estaba vacía y no había nadie con quien luchar, pero es alarde militar, bravuconada, no sabe mentir políticamente para obtener un cargo. Pavlovsky le da una vuelta de tuerca a su personaje él se niega a seguir la costumbre de mostrar las heridas para pedir los votos porque el pueblo no lo merece

Coriolano: [...] No tolero a los rebaños que esperan siempre lejos de los lugares de combate - para luego venir a juzgarnos o halagarnos. [...] quisiera que todos tuvieran tu coraje - que el rebaño se inundara de tu fuerza o de la mía - aunque sea con gritos y empujones - que se inundaran de alegría - que no los envolviera la tristeza - ¡El rebaño es triste Aufidio y la revolución será alegre o no será revolución! (Pavlovsky:77)

Coriolano arenga, tiene el poder de la palabra, su discurso enardece, es el poder de la poesía, es como si estuviese poseso, es la creación misma, no sabe lo que dice, no es calculador, es creativo pero para ser político, cónsul se necesita un lenguaje de artimañas.

Hay una inversión en la visión de la guerra: Coriolano y Aufidio muestran la guerra como alegría, carcajada y emprenden La gran marcha contra Roma y se utiliza un lenguaje rabelesiano para la descripción de los personajes a base de pedos y efluvios fecales. Coriolano es un cobarde, un cagón. Pavlovsky contrapone el estruendo de los pedos, la trompetería de pedos frente a la suciedad de la cobardía. Coriolano confiesa a su madre su cobardía, su valentía es a base de drogas, solo así puede soportar el peso del poder, el miedo es lo que lo rige por eso es valiente, porque combate con miedo.

El mensaje final del Coriolano de Pavlovsky es una inversión carnavalesca, es un llamamiento a la alegría popular, a la risa como medio de liberación:

Coriolano: Que las carcajadas inunden las calles de Roma. Que la alegría avance por los campos. ;Que irradie la alegría!

¡Viva Roma!

Corre Volumnia y envía el canto de alegría a mi pueblo chusma. Que el canto propague por toda la ciudad y la campiña - que las carcajadas canten mi existencia

idiles que les obligaron a ser tristes y mustios para siempre!

Pero que pueden ser alegres si se juntan todos - ique su fuerza será invencible - os lo prometo!

Bruto: ¡Detengan a Volumnia! [...] iNo muevan el rebaño nunca! ; Que permanezca triste y resignado! Esa es siempre la orden del Senado: la tristeza (Pavlovsky:92) 
Pavlovsky retoma la obra y le otorga un giro pantagruélico en donde la hiperbolización de los pedos, del miembro viril, de la carcajada de la fiesta popular, el poder creador de la risa, en síntesis, la inversión del mundo se hace posible. Es así como termina Volumnia o La gran marcha, con una estrepitosa carcajada.

\section{A modo de conclusión}

Bertold Brecht, en el contexto difícil que le tocó vivir, utilizó a los clásicos para distanciarse y poder re-pensar, ver con ojos diferentes, la cotidianeidad que lo rodeaba. Pensar que los sucesos son producto de determinadas relaciones sociales y no están signados, ni predeterminados, que verlos desde otro lugar, desde otro(s) punto(s) de vista, nos puede hacer concebir otras posibilidades, construir otras relaciones. Marlowe, en Eduardo I/ trabaja, al igual que Shakespeare en Rey Lear, el tema de la pérdida de poder, de cómo el rey pasa de ser la cabeza del estado a habitar el lugar más infecto de Londres donde desaguan todas las cloacas y toda la población defeca sobre el rey. Una vez más la degradación, la inversión de la que hablábamos, lo escatológico como principal desmitificador. Pero en este trayecto, también trabajado e hiperbolizado en la re-escritura de Brecht, mientras la versión isabelina focaliza en el capricho del rey Eduardo para mantener a su favorito Gavestone y las guerras que desencadena para mantenerlo, Brecht focaliza en la responsabilidad que conlleva el poder y sus consecuencias. Nuevamente para tratar este tema "serio" lo hace desde procedimientos farsescos:

\section{Risas}

Entra un vendedor de baladas

\section{Vendedor de baladas}

La manceba de Edi tiene barba en el pecho

iRuega por nosotros, ruega por nosotros, ruega por nosotros!

Y por eso la derrota en Escocia es un hecho. [...]

El despioja a su Gavi y eso es todo lo que hay.

¡Ruega por nosotros, ruega por nosotros, ruega por nosotros!

Y por eso perdió Johnny el pellejo en el pantano de Banobride. (Brecht, 1988:16)

Brecht escribe desde la Europa nazi del siglo XX, es como si en los momentos más coyunturales, el horror solo pudiera ser representado a través de textos de otros

En nuestra construcción y búsqueda de un algo que nos represente, las textualidades isabelinas son un material que nos proporciona una rica gama de posibilidades para repensar y desarticular modelos. Esas mismas textualidades contienen dentro se sí la impronta de la contradicción, la síntesis de la vigencia de dos modelos: uno en decadencia y otro pugnando por transformarse en hegemónico. En este límite, desde este lugar del borde, se asoma la mueca, la palabra del loco que deja al mundo sin sentido y que abre la puerta para la búsqueda de una identidad, que obviamente cuando logre definirse será necesariamente será degradada.

El sentido farsesco desde el que se abordan las re-creaciones de los textos isabelinos que hemos abordado, aporta algo de lo que Bajtin habla cuando define a la degradación como un fenómeno ambivalente.
Y lo "inferior" corporal, la zona de los órganos genitales, es lo "inferior" que fecunda y da a luz. Esta es la razón por la que las imágenes de la orina y los excrementos guardan un vínculo sustancial con el nacimiento, la fecundidad, la revocación y el bienestar. En la época de Rabelais, este aspecto positivo estaba aún vivo y era percibido claramente. (Bajtín:134)

Recuperar este aspecto positivo de la degradación parece ser la búsqueda en la que se encuentra el Coriolano de Pavlovski, y quizás por eso termina así: con una estrepitosa carcajada.

\section{Bibliografía}

- Alexander, M. (1979). An introduction to Shakespeare and his contemporaies, London: Pan Books.

Aristóteles (1979). Poética, Madrid: Aguilar.

Auden, W. (1999). El mundo de Shakespeare, Buenos Aires: Adriana Hidalgo Editora.

Barrow, R. H. (1980). Los romanos, México: FCE.

Bajtin, M. (1994). La cultura popular en la edad Media y en el Renacimiento. El contexto de Fracois Rabelais, Buenos Aires: Alianza.

- Bloom, H. (2001). Shakespeare. La invención de lo humano, Bogotá: Grupo Editorial Norma.

Benjamin, W. (1991). Tentativas sobre Brecht, Madrid: Taurus. Bentley, E. (1982). La vida del drama, Buenos Aires: Paidós.

Berger, P. (1971). El dosel sagrado. Elementos para una sociología de la religión. Buenos Aires: Amorrortu.

- Brecht, B. (1988). Vida de Eduardo /l de Inglaterra. Historia (según Marlowe), Madrid: Alianza.

(1959). Coriolan. Frankfurt: Stüke, vol. XI (tr. Coriolano, Buenos Aires: Nueva Visión, 1981)

--(1957). Schrifen zum Theater. Frankfurt: Suhrkamp Verlag (tr. Escritos sobre Teatro, Buenos Aires: Nueva Visión, 1970) -(1949). Kleines Organon für das Theater. (tr. Breviario de Estética teatral, Buenos Aires: La Rosa Blindada, 1963)

Brecht, B., Groz, G., Piscator, E. (1979). Arte y sociedad, Buenos Aires: Caldén.

- Bregazzi, J. (1999). Shakespeare y el teatro renanacentista inglés, Madrid: Alianza Editorial.

- Brook, P. (1993). The open door. Thoughts on Acting and Theatre. (tr. La puerta abierta. Reflexiones sobre la interpretación y el teatro, Barcelona: Alba Editorial, 1994, 1999)

-(1968). The empty space (tr. El espacio vació, Barcelona:

Península, 1973)

Dubatti, J. (2004). "Shakespeare ¿nuestro contemporáneo?" en Teatro al Sur № 27, Buenos Aires: Noviembre de 2004, pp. 6-10.

Cabrera, H. (2006). "El derrumbe en tonos de gris" en Página/12, Buenos Aires: 8/7/07.

Gamerro, C. (2003) "Masa y poder" en Radar, Página 12, Buenos Aires, 07/ 09/03.

Gonzalez, J. M. (1993). El teatro de William Shakespeare hoy. Una interpretación radical actualizada, Barcelona: Montesinos.

Ingberg, P. (2006). "El teatro no debe caer en lo abstracto". Entrevista a Jorge Lavelli en Revista N. Buenos Aires: 3/6/2006.

Iriarte Nuñez, A. (1998). Lo teatral en la obra de Shakespeare. Análisis de algunos aspectos escénicos en los dramas del isabelinos, vistos a la luz de la teoría teatral del siglo XX, Colombia: Ed. Universidad de Antioquía.

- Jitrik, N. (1993). "Rehabilitación de la parodia" en La parodia en la literatura latinoamericana, Buenos Aires: FFyLE, UBA.

- Kott, I. (1969). Apuntes sobre Shakespeare, Barcelona:Seix Barral.

- Lavelli, J. (2006). Rey Lear, Buenos Aires: Complejo Teatral de Buenos Aires. 
- Oliva, C. (1998). Historia básica del arte escénico, Madrid: Cátedra. - Pavlovsky, E. (2005). Teatro completo 4, Buenos Aires: Atuel.

- Shakespeare, W. (1961). Obras Completas, Madrid: Aguilar.

- Tortonese, H., Urdapilleta, A. (1997). La moribunda, Buenos Aires: Morocco.
Trillo- Figueroa, F. (1999). El poder político en los dramas de Shakespeare, Madrid: Espasa. Recuperado de http://www.sparknotes.com/shakespeare/coriolanus/context.html 